\title{
Implementasi K-Means Clustering Ujian Nasional Sekolah Menengah Pertama di Indonesia Tahun 2018/2019
}

\author{
Agil Aditya, Ivan Jovian, Betha Nurina Sari \\ Fakultas Ilmu Komputer, Teknik Informatika, Universitas Singaperbangsa Karawang, Karawang, Indonesia \\ Email: ${ }^{1}$ agil.16017@ student.unsika.ac.id, ${ }^{2}$ ivan.16122@ student.unsika.ac.id, ${ }^{3}$ betha.nurina@ staff.unsika.ac.id
}

\begin{abstract}
Abstrak-Klastering merupakan kegiatan yang bertujuan untuk mengelompokan suatu data yang memiliki sebuah kemiripan antara satu data dengan data lainnya. K-Means clustering merupakan salah satu metode data clustering non hirarki yang berusaha mempartisi data yang ada ke dalam bentuk satu atau lebih cluster/kelompok. Pada penelitian ini dilakukan clustering dengan menggunakan algoritma K-Means menggunakan data capaian Ujian Nasional Sekolah Menengah Pertama pada tahun 2018/2019 yang diperoleh dari website resmi Pusat Penilaian Pendidikan dan Kebudayaan Kementrian Pendidikan dan Kebudayaan Republik Indonesia. Hasil cluster dengan algoritma K-Means didapatkan untuk cluster 1 terdapat 14 provinsi, cluster 2 terdapat 5 provinsi, dan cluster 3 terdapat 15 provinsi. Tingkatan cluster 1 adalah cluster dengan nilai ujian nasional Tinggi, cluster 2 adalah cluster dengan nilai ujian nasional Rendah dan cluster 3 adalah cluster dengan nilai ujian nasional Sedang. Sedangkan hasil evaluasi dari algoritma K-Means dengan jumlah kluster 3 menghasilkan nilai evaluasi Connectivity 11.916, Dunn 0.246 dan Silhouette 0.464.
\end{abstract}

Kata Kunci: Klastering, Data Mining, K-Means, Pengukuran Jarak Euclidean, Ujian Nasional

Abstract-Clustering is an activity that aims to group a data that has a similarity between one data with another data. K-Means clustering is a non-hierarchical data clustering method that attempts to partition existing data into one or more clusters / groups. In this study clustering was conducted using the K-Means algorithm using data on the achievements of the National Middle School National Examination in 2018 obtained from the official website of the Center for Education and Culture Assessment of the Ministry of Education and Culture of the Republic of Indonesia. The results of the cluster with the K-Means algorithm are obtained for cluster 1 there are 14 provinces, cluster 2 there are 5 provinces, and cluster 3 there are 15 provinces with cluster 1 level is a cluster with a high national test score, cluster 2 is a cluster with a low national test score and a cluster 3 is a cluster with moderate national examination scores. While the results of the evaluation of the K-Means algorithm with the number of clusters 3 produce an evaluation value of Connectivity 11,916, Dunn 0.246 and Silhouette 0.464.

Keywords: Clustering, Data Mining, K-Means, Euclidean Distance, National Exam

\section{PENDAHULUAN}

Clustering merupakan aktivitas (task) yang bertujuan mengelompokkan data yang memiliki kemiripan antara satu data dengan data lainnya ke dalam klaster atau kelompok sehingga data dalam satu klaster memiliki tingkat kemiripan (similiarity) yang maksimum dan data antar klaster memiliki kemiripan yang minimum. Clustering juga dapat diartikan metode segmentasi data yang diimplementasikan dalam beberapa bidang, di antaranya marketing, analisa masalah bisnis segmentasi pasar dan prediksi, pola dalam bidang computer vision, zonasi wilayah hingga identifikasi obyek dan pengolahan citra.

Analisis klaster bertujuan menemukan kelompok objek sedemikian rupa sehingga objek-objek dalam grup akan sama (atau terkait) satu sama lain dan berbeda dari (atau tidak terkait) objek-objek dalam grup lain [1]. $K$ Means Clustering merupakan salah satu metode data clustering non hirarki yang berusaha mempartisi data yang ada ke dalam bentuk satu atau lebih cluster/kelompok [2]. K-Means yaitu salah satu dari metode pengelompokan data nonhierarki (sekatan) yang dapat mempartisi data ke dalam bentuk dua kelompok ataupun lebih. Metode tersebut akan mempartisi data k edalam suatu kelompok dimana data yang berkarakteristik sama akan dimasukkan ke dalam satu kelompok sama sedangkan data yang memiliki karakteristik yang berbeda akan dikelompokan ke dalam kelompok lainnya [3].

Pada penelitian ini dilakukan clustering dengan menggunakan algoritma $K$-Means menggunakan data capaian Ujian Nasional Sekolah Menengah Pertama pada tahun 2018/2019 yang diperoleh dari website resmi Pusat Penilaian Pendidikan dan Kebudayaan Kementrian Pendidikan dan Kebudayaan Republik Indonesia. Clustering dilakukan untuk mengelompokan provinsi mana saja di Republik Indonesia yang memiliki nilai Ujian Nasional tingkat Sekolah Menengah Pertama yang rendah, sedang dan tinggi, sehingga nantinya dapat dijadikan bahan evaluasi terhadap hasil ujian di tiap-tiap provinsi.

\section{METODE PENELITIAN}

\subsection{Data Mining}

Data Mining adalah proses yang menggunakan teknik statistik, matematika, kecerdasan buatan, dan machine learning untuk mengekstrasi dan mengidentifikasi informasi yang bermanfaat dan pengetahuan yang terkait dari berbagai database besar [2]. Menurut Kusrini Data Mining adalah suatu istilah yang digunakan untuk menguraikan penemuan pengetahuan di dalam database. Data Mining adalah proses yang menggunakan teknik statistik, 
matematika, kecerdasan buatan dan machine learning untuk menginteraksi mengidentifikasi informasi yang bermanfaat dan pengetahuan yang terikat dari berbagai database besar [4].

\subsection{Clustering}

Clustering merupakan salah satu teknik dari salah satu fungsionalitas data mining, algoritma clustering merupakan algoritma pengelompokan sejumlah data menjadi kelompok-kelompok data tertentu (cluster) [4]. Pada proses clustering, tahapan menentukan atau mendeskripsikan nilai kuantitatif dari tingkat kemiripan atau ketidakmiripan data (proximity measure) memiliki peranan sangat penting, sehingga perlu dilakukannya perbandingan beberapa metode yang sering digunakan, yaitu jarak euclidean, manhattan, dan minkowski [1]. Clustering merupakan salah satu teknik pengelompokan data berdasarkan kesamaan karakteristik data. Clustering-based memiliki beberapa tipe penting, diantaranya Partitional Clustering. Partitional Clustering merupakan pembagian data ke dalam sebuah himpunan data (cluster) yang tidak overlap sedemikian setiap data berada dalam satu cluster saja [5].

\subsection{K-Means}

K-Means pertama kali dipublikasikan oleh Stuart Lloyd pada tahun 1984 dan merupakan algoritma clustering yang banyak digunakan. K-Means bekerja dengan mensegmentasi objek yang ada ke dalam kelompok atau yang disebut dengan segmen sehingga objek yang berada dalam masing-masing kelompok lebih serupa satu sama lain dibandingkan dengan objek dalam kelompok yang berbeda [6]. K-means menggunakan ukuran Euclidean distance dan secara iteratif menentukan tiap record dari cluster asal. Prosedur dimulai dengan memilih k dengan initial records sebagai pusat cluster (initial seed) dan menentukan setiap record yang paling dekat dengan cluster. Record baru ditambahkan ke cluster, cluster center dihitung ulang untuk mencerminkan anggota baru mereka. Prosedur iterasi ini diulang sampai konvergen dan migrasi record dengan cluster tidak lagi menyaring solusinya [7]. KMeans merupakan algoritma heuristik yang memisah kumpulan data ke dalam klaster K dengan meminimalkan jumlah jarak kuadrat di setiap klaster [1]. Prinsip uatama dari teknik ini adalah menyusun K buah partisi/pusat massa (centroid)/rata-rata (mean) dari sekupulan data. Algoritma K-Means dimulai dengan pembentukan partisi klaster diawal kemudian secara iteraktif partisi cluster ini diperbaiki hingga tidak terjadi perubahan yang signifikan pada partisi cluster [4].

\subsection{Euclidean Distance}

Euclidean distance adalah metode yang digunakan untuk mengukur jarak antara 2 titik yang berbeda [8]. Adapun rumus yang digunakan adalah :

$$
\mathrm{d}(\mathrm{i}, \mathrm{j})=\sqrt{\left|\mathrm{X}_{i 1}-\mathrm{X}_{j 1}\right|^{2}+\left|\mathrm{X}_{i 2}-\mathrm{X}_{j 2}\right|^{2}+\cdots+\left|\mathrm{X}_{i p}-\mathrm{X}_{j p}\right|^{2}}
$$

Dengan D adalah jarak antara titik pada data $\mathrm{x}$ dan titik data $\mathrm{y}$, dimana $\mathrm{x}=\mathrm{x} 1, \mathrm{x} 2, \ldots \ldots \mathrm{xi}$ dan $\mathrm{y}=\mathrm{y} 1$, y2,.....yi dan $\mathrm{j}$ mempresentasikan nilai atribut serta $\mathrm{p}$ merupakan dimensi atribut.

Keterangan :

$d(i, j)=$ jarak euclidean

$X i=$ nilai titik 1

$X j=$ nilai titik 2

\subsection{Elbow Method}

Elbow Method adalah metode yang digunakan untuk menginterpretasikan dan uji performa tingkat konsistensi jumlah cluster yang tepat dengan melihat nilai SSE [9]. Pada titik tertentu akan terjadi grafik penurunan secara drastis dengan sebuah lekukan yang disebut dengan kriteria siku. Nilai itu kemudian menjadi nilai k atau jumlah cluster yang terbaik [9]. Untuk mendapatkan perbandingannya adalah dengan menghitung SSE (Sum of Square Error) dari masing-masing nilai cluster. Karena semakin besar jumlah cluster K maka nilai SSE akan semakin kecil. Rumus SSE pada K-Means dapat dilihat pada formula 2.

$$
S S E=\sum_{i=1}^{n}(X i-\bar{X})^{2}
$$

\subsection{Cluster Validation}

Untuk mengatasi kesulitan algoritma $K$-Means dalam menentukan jumlah klaster yang tepat berdasarkan data yang digunakan, maka digunakan indeks validitas yang merupakan metode untuk mengevaluasi hasil algoritma clustering dengan tujuan mendapatkan jumlah klaster terbaik [10]. Pada penelitian ini digunakan tiga indeks validitas yaitu Silhouette, Dunn, dan Connectivity. Adapun penjelasan mengenai validitas tersebut disebutkan di bawah ini :

a. Silhouette

Indeks validitas Silhouette menghitung rata-rata nilai setiap titik pada himpunan data. perhitungan nilai setiap titik adalah selisih nilai separation dan compactness yang dibagi dengan maksimum antara keduanya. Jumlah 
JURNAL MEDIA INFORMATIKA BUDIDARMA

Volume 4, Nomor 1, Januari 2020, Page 51-58

ISSN 2614-5278 (media cetak), ISSN 2548-8368 (media online)

Available Online at https://ejurnal.stmik-budidarma.ac.id/index.php/mib

DOI $10.30865 /$ mib.v4i1.1784

klaster yang terbaik ditunjukkan dengan nilai Silhouette yang semakin mendekati 1 [10]. dapat dilihat rentang nilai dan interpretasi pada tabel I [11].

Tabel 1. Rentang nilai Silhouette dan interpretasi

\begin{tabular}{ll}
\hline Rentang nilai & Interpretasi \\
\hline $0.71-1.0$ & Struktur yang kuat \\
$0.51-0.70$ & Struktur yang beralasan \\
$0.26-0.50$ & Struktur lemah \\
$<0.25$ & Tidak ditemukan struktur yang substansial \\
\hline
\end{tabular}

b. Dunn

Indeks validitas Dunn (DN) menghitung nilai minimum dari perbandingan antara nilai fungsi dissimilaritas antara dua klaster sebagai separation dan nilai maksimum dari diameter klaster sebagai compactness. Jumlah klaster terbaik ditunjukkan dengan semakin besar nilai DN [10].

c. Connectivity

Dalam jurnalnya mengatakan "Connectivity is calculated by finding the $\mathrm{n}$ closest pathways to each pathway, then adding $1 / \mathrm{n}$ to the total connectivity value if the nth closest pathway is in a different cluster than the first pathway" [12]. Nilai ini berkisar dari nol hingga tak terhingga, di mana nilai yang lebih kecil menunjukkan kluster kualitas yang lebih baik [12].

\section{ANALISA DAN PEMBAHASAN}

\subsection{Dataset}

Data yang digunakan adalah data hasil Ujian Nasional tingkat Sekolah Menengah Pertama (SMP) yang didapat dari website resmi Kementrian Pendidikan Dan Kebudayaan Republik Indonesia [13]. Data yang digunakan adalah data tahun 2018/2019 dengan jumlah data 34 dengan 10 Atribut yaitu Nama Provinsi, Jumlah Satuan Pendidikan, Jumlah peserta, Rata-Rata Nilai Matematika, Bahasa Indonesia, Bahasa Inggris, IPA, dan Rata-Rata Nilai Provinsi.

\subsection{Metode}

Untuk melakukan clustering menggunakan algoritma K-Means pada penelitian ini, digunakan tahapan-tahapan dari metode KDD (Knowledges Discovery in Databases). Adapun tahapan dari metode KDD adalah data selection, data pre-processing, data integration, data transformation, data mining, dan evaluation [14][3]. Berikut alur penelitian penerapan algoritma K-Means untuk clustering provinsi mana saja di Republik Indonesia hasil nilai Ujian Nasional tingkat Sekolah Menengah Pertama yang rendah dan tinggi. Adapun alur penelitian terdapat pada gambar 1 .

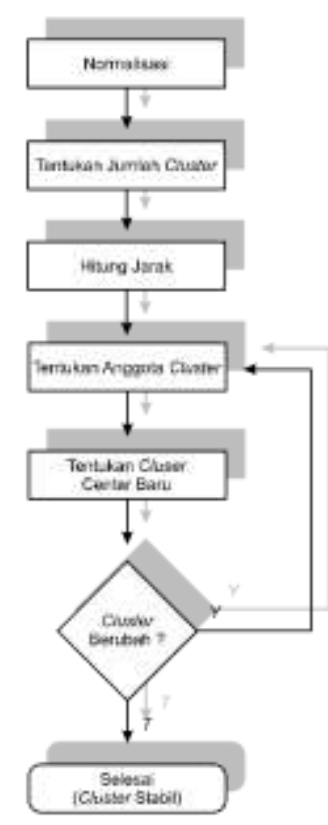

Gambar 1. Alur Penelitan 
JURNAL MEDIA INFORMATIKA BUDIDARMA

Volume 4, Nomor 1, Januari 2020, Page 51-58

ISSN 2614-5278 (media cetak), ISSN 2548-8368 (media online)

Available Online at https://ejurnal.stmik-budidarma.ac.id/index.php/mib DOI $10.30865 /$ mib.v4i1.1784

\subsubsection{Data Selection}

Data yang digunakan dalam penelitian ini adalah dengan menggunakan data Ujian Nasional Republik Indonesia tingkat SMP/MTS/sederajat tahun 2018/2019 yang bersumber dari Puspendik Kemendikbud . Data ini memiliki 34 data yang terdiri dari 10 atribut. Keterangan data dapat dilihat pada tabel 1.

Tabel 2. Keterangan dataset awal

\begin{tabular}{lll}
\hline Atribut & Tipe data & Keterangan \\
\hline No & Numerik & Nomer urut \\
Kode & Numerik & Kode Provinsi \\
Nama Provinsi & Nominal & Nama Provinsi \\
Jumlah Satuan & Numerik & $\begin{array}{l}\text { Banyaknya satuan } \\
\text { pendidikan di } \\
\text { Pendidikan }\end{array}$ \\
& & $\begin{array}{l}\text { Provinsi } \\
\text { Banyaknya peserta } \\
\text { ujian tiap Provinsi }\end{array}$ \\
Jumlah Peserta & Numerik & Hasil nilai Bahasa \\
Rerata Nilai & Numerik & Indonesia tiap \\
Bahasa & & Provinsi \\
Indonesia & & Hasil nilai Bahasa \\
Rerata Nilai & Numerik & Inggris tiap \\
Bahasa Inggris & & Provinsi \\
Rerata Nilai & Numerik & Hasil nilai Bahasa \\
Matematika & & Matematika tiap \\
& & Provinsi \\
Rerata Nilai & Numerik & Hasil nilai Bahasa \\
IPA & & IPA tiap Provinsi \\
Rerata Nilai & Numerik & Hasil rerata nilai \\
& & keseluruhan \\
\hline
\end{tabular}

Dari dataset awal yang didapat dilakukan proses seleksi, dimana atribut-atribut yang digunakan yaitu : Nama provinsi, Bahasa Indonesia, Bahasa Inggris, Matematika, dan Ipa. Maka akan terlihat perubahannya seperti tabel 2 dibawah ini:

Tabel 3. Dataset hasil seleksi

\begin{tabular}{lll}
\hline Atribut & Tipe data & Keterangan \\
\hline Nama Provinsi & Nominal & Nama Provinsi \\
Rerata Nilai & Numerik & Hasil nilai Bahasa \\
Bahasa & & Indonesia tiap \\
Indonesia & & Provinsi \\
Rerata Nilai & Numerik & Hasil nilai Bahasa \\
Bahasa Inggris & & Inggris tiap \\
& & Provinsi \\
Rerata Nilai & Numerik & Hasil nilai Bahasa \\
Matematika & & Matematika tiap \\
& & Provinsi \\
Rerata Nilai & Numerik & Hasil nilai Bahasa \\
IPA & & IPA tiap Provinsi \\
\hline
\end{tabular}

\subsubsection{Data pre-processing/cleaning}

Dalam penelitian ini tidak ditemukan null maka dilakukan langkah selanjutnya. Karena tidak terdapat missing values maka dilakukan langkah untuk mencegah outlier menggunakan normalisasi dengan teknik scalling [15].

Tabel 4. Dataset nilai ujian nasional 2018/2019

\begin{tabular}{l|c|c|c|c}
\hline \multirow{2}{*}{\multicolumn{1}{c|}{ NAMA PROVINSI }} & \multicolumn{3}{c}{ RERATA NILAI PADA MATA UJI } \\
\cline { 2 - 5 } & $\begin{array}{c}\text { BAHASA } \\
\text { INDONESIA }\end{array}$ & $\begin{array}{c}\text { BAHASA } \\
\text { INGGRIS }\end{array}$ & MATEMATIKA & \multirow{2}{*}{ IPA } \\
\hline DKI JAKARTA & 72.88 & 60.98 & 53.26 & 55.71 \\
JAWA BARAT & 64.24 & 50.64 & 46.14 & 47.74 \\
JAWA TENGAH & 70.85 & 50.83 & 49.28 & 52.54 \\
DI YOGYAKARTA & 78.15 & 58.73 & 60.22 & 61.16 \\
JAWA TIMUR & 67.25 & 51.15 & 48.03 & 50.89
\end{tabular}


JURNAL MEDIA INFORMATIKA BUDIDARMA

Volume 4, Nomor 1, Januari 2020, Page 51-58

ISSN 2614-5278 (media cetak), ISSN 2548-8368 (media online)

Available Online at https://ejurnal.stmik-budidarma.ac.id/index.php/mib DOI $10.30865 /$ mib.v4i1.1784

\begin{tabular}{lcccc} 
ACEH & 54.57 & 43.12 & 38.79 & 40.95 \\
SUMATERA UTARA & 59.17 & 47.12 & 43.6 & 44.87 \\
SUMATERA BARAT & 68.83 & 47.85 & 46.76 & 49.31 \\
RIAU & 65.16 & 48.45 & 46.06 & 47.67 \\
JAMBI & 60.12 & 45.14 & 41.26 & 43.45 \\
SUMATERA SELATAN & 58.12 & 43.86 & 40.34 & 41.85 \\
LAMPUNG & 62 & 44.39 & 40.03 & 42.88 \\
KALIMANTAN BARAT & 62.32 & 45.05 & 40.52 & 42.78 \\
KALIMANTAN TENGAH & 63.65 & 48.51 & 45.04 & 46.29 \\
KALIMANTAN SELATAN & 66.59 & 48.85 & 42.05 & 47.08 \\
KALIMANTAN TIMUR & 68.82 & 51.32 & 44.12 & 47.92 \\
SULAWESI UTARA & 57.71 & 47.46 & 40.84 & 43.72 \\
SULAWESI TENGAH & 60.33 & 44.48 & 41.12 & 43.71 \\
SULAWESI SELATAN & 59.97 & 46.33 & 42.47 & 45.26 \\
SULAWESI TENGGARA & 61.8 & 45.75 & 44.47 & 45.65 \\
MALUKU & 60.3 & 51.69 & 50.47 & 48.98 \\
BALI & 69.42 & 52.19 & 43.87 & 49.03 \\
NUSA TENGGARA BARAT & 56.87 & 43.26 & 38.76 & 41.79 \\
NUSA TENGGARA TIMUR & 64.75 & 45.9 & 46.29 & 45.78 \\
PAPUA & 58.76 & 48.46 & 46.23 & 47.63 \\
BENGKULU & 62.61 & 43.81 & 39.74 & 42.78 \\
MALUKU UTARA & 58.49 & 52.6 & 49.15 & 50.07 \\
BANGKA BELITUNG & 67.89 & 48.33 & 44.34 & 47.9 \\
GORONTALO & 56.04 & 44.69 & 40.74 & 43.51 \\
BANTEN & 60.29 & 48.1 & 41.91 & 43.98 \\
KEPULAUAN RIAU & 70.19 & 54.25 & 47.5 & 50.18 \\
SULAWESI BARAT & 55.4 & 42.09 & 39.68 & 40.45 \\
PAPUA BARAT & 61.11 & 49.51 & 48.28 & 48.96 \\
KALIMANTAN UTARA & 64.45 & 47.55 & 42.4 & 45.04 \\
\hline
\end{tabular}

Adapun tahap proses yang dilakukan dalam tahap normalisasi ini yaitu:

a. Mencari nilai maksimum dan minimum dari masing-masing kolom atau variable.

Contoh kita akan mengambil variable rerata nilai pada mata uji Bahasa Indonesia maka didapat:

Nilai maksimum $($ Xmaks $)=78.18$

Nilai minimum $(\mathrm{Xmin})=54.79$

b. Menghitung nilai normalisasi menggunakan persamaan :

$$
\text { Normalisasi }=\frac{(\text { Nilai awal-Nilai minimal })}{(\text { Nilai maksimal-Nilai Minimal })}
$$

c. Menghitung nilai normalisasi menggunakan persamaan diatas:

$$
\begin{aligned}
& \mathrm{XF6}=(\mathrm{XF6}-\mathrm{Xmin}) /(\mathrm{Xmaks}-\mathrm{Xmin}) \\
& =(72.88-54.79) /(78.18-54.79)=0.77
\end{aligned}
$$

Lakukan langkah yang sama hingga nilai normalisasi sudah terisi pada kolom mata pelajaran Bahasa Indonesia, lakukan hal yang sama juga pada kolom atau variable nilai Bahasa Inggris, Matematika dan IPA. Maka didapat hasil seperti gambar 3 .

Tabel 5. Dataset hasil scaling

\begin{tabular}{cccc}
\hline $\mathrm{X} 1$ & $\mathrm{X} 2$ & $\mathrm{X} 3$ & $\mathrm{X} 4$ \\
\hline 0.78 & 1 & 0.68 & 0.74 \\
0.41 & 0.45 & 0.34 & 0.35 \\
0.69 & 0.46 & 0.49 & 0.58 \\
1 & 0.88 & 1 & 1 \\
0.54 & 0.48 & 0.43 & 0.5 \\
0 & 0.05 & 0 & 0.02 \\
0.2 & 0.27 & 0.23 & 0.21 \\
0.6 & 0.3 & 0.37 & 0.43 \\
0.45 & 0.34 & 0.34 & 0.35 \\
0.24 & 0.16 & 0.12 & 0.14
\end{tabular}


JURNAL MEDIA INFORMATIKA BUDIDARMA

Volume 4, Nomor 1, Januari 2020, Page 51-58

ISSN 2614-5278 (media cetak), ISSN 2548-8368 (media online)

Available Online at https://ejurnal.stmik-budidarma.ac.id/index.php/mib DOI $10.30865 /$ mib.v4i1.1784

\begin{tabular}{cccc}
0.15 & 0.09 & 0.07 & 0.07 \\
0.32 & 0.12 & 0.06 & 0.12 \\
0.33 & 0.16 & 0.08 & 0.11 \\
0.39 & 0.34 & 0.29 & 0.28 \\
0.51 & 0.36 & 0.15 & 0.32 \\
0.6 & 0.49 & 0.25 & 0.36 \\
0.13 & 0.28 & 0.1 & 0.16 \\
0.24 & 0.13 & 0.11 & 0.16 \\
0.23 & 0.22 & 0.17 & 0.23 \\
0.31 & 0.19 & 0.27 & 0.25 \\
0.24 & 0.51 & 0.55 & 0.41 \\
0.63 & 0.53 & 0.24 & 0.41 \\
0.1 & 0.06 & 0 & 0.06 \\
0.43 & 0.2 & 0.35 & 0.26 \\
0.18 & 0.34 & 0.35 & 0.35 \\
0.34 & 0.09 & 0.05 & 0.11 \\
0.17 & 0.56 & 0.48 & 0.46 \\
0.56 & 0.33 & 0.26 & 0.36 \\
0.06 & 0.14 & 0.09 & 0.15 \\
0.24 & 0.32 & 0.15 & 0.17 \\
0.66 & 0.64 & 0.41 & 0.47 \\
0.04 & 0 & 0.04 & 0 \\
0.28 & 0.39 & 0.44 & 0.41 \\
0.42 & 0.29 & 0.17 & 0.22 \\
\hline
\end{tabular}

\subsubsection{Data Integration}

Setelah proses data cleaning dilakukan maka selanjutnya adalah melakukan data integration yaitu dengan menggabungkan semua dataset ke dalam satu tabel. Dikarenakan data hanya menggunakan satu tabel maka tahap ini tidak dilakukan.

\subsubsection{Data Transformation}

Pada tahap ini dilakukan perubahan nama variabel untuk memudahkan proses data mining seperti yang terlihat pada tabel 6 di bawah ini:

Tabel 6. Pengantian nama variabel data

\begin{tabular}{lc}
\hline $\begin{array}{c}\text { Nama Variabel } \\
\text { Lama }\end{array}$ & $\begin{array}{c}\text { Nama Variabel } \\
\text { baru }\end{array}$ \\
\hline $\begin{array}{l}\text { Nama Provinsi } \\
\text { Rerata Nilai }\end{array}$ & $\mathrm{X}$ \\
Bahasa & $\mathrm{X} 1$ \\
$\begin{array}{l}\text { Indonesia } \\
\text { Rerata Nilai } \\
\text { Bahasa Inggris }\end{array}$ & $\mathrm{X} 2$ \\
$\begin{array}{l}\text { Rerata Nilai } \\
\text { Matematika }\end{array}$ & $\mathrm{X} 3$ \\
Rerata Nilai & \\
IPA & $\mathrm{X} 4$ \\
\hline
\end{tabular}

\subsection{Data Mining}

Untuk skenario yang digunakan algoritma yang digunakan adalah algoritma K-Means, dengan jumlah cluster hasil penentuan metode elbow [9] sejumlah 3 dapat dilihat pada gambar 4. Hasil cluster dengan algoritma $K$-Means didapatkan untuk cluster 1 terdapat 14 provinsi, cluster 2 terdapat 5 provinsi, dan cluster 3 terdapat 15 provinsi dengan tingkatan cluster 1 adalah cluster dengan nilai ujian nasional Tinggi, cluster 2 adalah cluster dengan nilai ujian nasional Rendah dan cluster 3 adalah cluster dengan nilai ujian nasional Sedang, dapat dilihat digambar 5 dan tabel 4, 5 dan 6. Diharapkan adalah nilai evaluasi dengan menggunakan cluster validation menunjukan nilai evaluasi yang tertinggi. Pada tahap ini dilakukan dengan bantuan tools R-Studio [16]. 


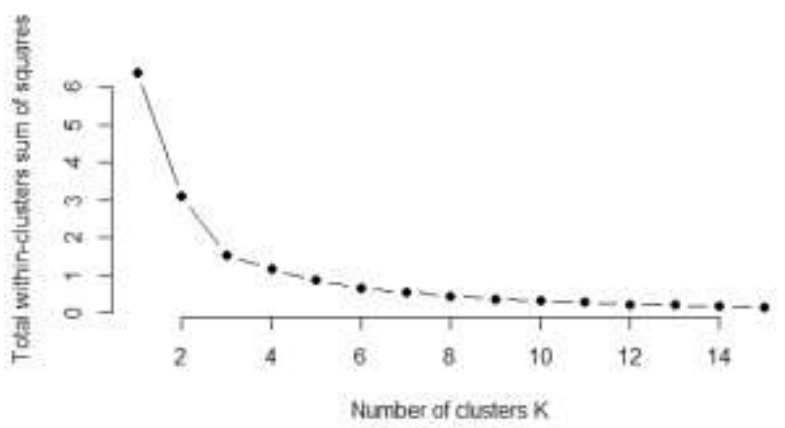

Gambar 4. Metode elbow

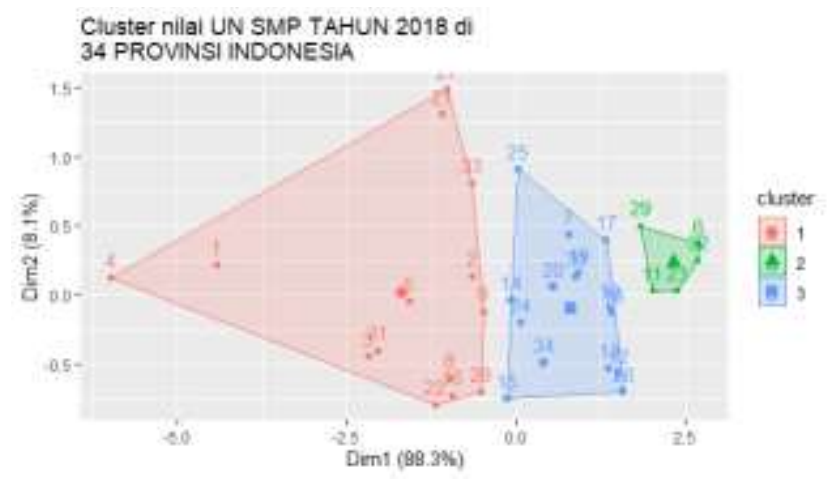

Gambar 4. Hasil clustering

Tabel 7. Hasil clustering

\begin{tabular}{|c|c|c|c|c|}
\hline Cluster & Anggota & Jumlah & Karakteristik & Kriteria \\
\hline Cluster 1 & $\begin{array}{l}\text { DKI Jakarta, Jawa } \\
\text { Barat, Jawa Tengah, DI } \\
\text { Yogyakarta, Jawa } \\
\text { Timur, Sumatera Barat, } \\
\text { Riau, Kalimantan } \\
\text { Timur, Maluku, Bali, } \\
\text { Maluku Utara, Bangka } \\
\text { Belitung, Kepulauan } \\
\text { Riau, Papua Barat }\end{array}$ & 14 & $51,54-64,67$ & Tinggi \\
\hline Cluster 2 & $\begin{array}{l}\text { Aceh, Sumatera Selatan, } \\
\text { Nusa Tenggara Barat, } \\
\text { Gorontalo, Sulawesi } \\
\text { Barat }\end{array}$ & 5 & $44,36-46,25$ & Rendah \\
\hline Cluster 3 & $\begin{array}{lr}\text { Sumatera Utara, Jambi, } \\
\text { Lampung, Kalimantan } \\
\text { Barat, Sulawesi Utara, } \\
\text { Sulawesi r Selatan, } \\
\text { Sulawesi Tengah, Nusa } \\
\text { Tenggara r Timur, } \\
\text { Bengkulu, } \\
\text { Sulawesi } & \text { Tenggaren, } \\
\text { Kalimantan } & \text { Tengah, } \\
\text { Kalimantan } & \text { Selatan, } \\
\text { Papua, Kalimantan } \\
\text { Utara }\end{array}$ & 15 & $47,24-51,14$ & Sedang \\
\hline
\end{tabular}




\subsection{Evaluasi}

Hasil dari algoritma K-Means dengan jumlah kluster 3 menghasilkan nilai evaluasi Connectivity 11.916, Dunn 0.246 dan Silhouette 0.464 (struktur data lemah).

\section{KESIMPULAN}

Penerapan algoritma $K$-Means dalam clustering nilai ujian nasional dapat diterapkan. Penerapan algoritma $K$ Means dengan metode KDD yang terdiri dari beberapa tahapan yaitu data cleaning, data integration, data selection, transformation, data mining, evaluation. Kemudian dilakukan validasi cluster untuk mengetahui hasil evaluasi cluster. Hasil cluster dengan algoritma K-Means didapatkan untuk cluster 1 terdapat 14 provinsi, cluster 2 terdapat 5 provinsi, dan cluster 3 terdapat 15 provinsi dengan tingkatan cluster 1 adalah cluster dengan nilai ujian nasional Tinggi, cluster 2 adalah cluster dengan nilai ujian nasional Rendah dan cluster 3 adalah cluster dengan nilai ujian nasional Sedang. Sedangkan hasil evaluasi dari algoritma K-Means dengan jumlah kluster 3 menghasilkan nilai evaluasi Connectivity 11.916, Dunn 0.246 dan Silhouette 0.464 (struktur data lemah). Diharapkan pada penelitian selanjutnya dapat menggunakan metode evaluasi lain seperti external measure dan menggunakan algoritma berbeda sehingga mendapatkan hasil yang lebih baik dan kesimpulan yang baru.

\section{REFERENCES}

[1] M. Nishom, "Perbandingan Akurasi Euclidean Distance, Minkowski Distance, dan Manhattan Distance pada Algoritma K- Means Clustering berbasis Chi-Square," J. Inform. J. Pengemb. IT, vol. 04, no. 01, pp. 20-24, 2019.

[2] M. Anggara, H. Sujiani, and H. Nasution, "Pemilihan Distance Measure Pada K-Means Clustering Untuk Pengelompokkan Member Di Alvaro Fitness," J. Sist. dan Teknol. Inf., vol. 1, no. 1, pp. 1-6, 2016.

[3] M. H. Adiya and Y. Desnelita, "Jurnal Nasional Teknologi dan Sistem Informasi Penerapan Algoritma K-Means Untuk Clustering Data Obat-Obatan Pada RSUD Pekanbaru," J. Nas. Teknol. DAN Sist. INFORMAS, vol. 05, no. 1, pp. 17-24, 2019.

[4] F. L. Sibuea and A. Sapta, "PEMETAAN SISWA BERPRESTASI MENGGUNAKAN METODE K-MEANS CLUSTERING,” JURTEKSI (Jurnal Teknol. dan Sist. Informasi), vol. IV, no. 1, 2017.

[5] T. W. P. A.A.Ngr Wisnu Gautama, Yudha Purwanto, "Analisis Pengaruh Penggunaan Manhattan Distance Pada Algoritma Clustering Isodata ( Self- Organizing Data Analysis Technique) Untuk Sistem Deteksi Anomali Trafik," eProceeding Eng., vol. 2, no. 3, pp. 7404-7411, 2015.

[6] R. Andrea, S. Palupi, and S. Qomariah, "CLUSTERING TIPE BELAJAR SISWA SMKN 2 PENAJAM PASER UTARA DENGAN PENERAPAN METODE DATA MINING K-MEANS DAN FUZZY C-MEANS ( FCM ) CLUSTER ANALYSIS FOR LEARNING STYLE OF VOCATIONAL HIGH SCHOOL STUDENT USING K-MEANS AND FUZZY C-MEANS ( FCM )," J. Penelit. Pos dan Inform., vol. 7, no. 2, pp. 121-128, 2017.

[7] C. D. Rumiarti and I. Budi, "SEGMENTASI PELANGGAN PADA CUSTOMER RELATIONSHIP MANAGEMENT DI PERUSAHAAN RITEL: STUDI KASUS PT GRAMEDIA ASRI MEDIA,” J. Sist. Inf. ( J. Inf. Syst. ), vol. 13, pp. $1-10,2017$.

[8] R. Rizaldi, A. Kurniawati, and C. V. Angkoso, "Implementasi Metode Euclidean Distance untuk Rekomendasi Ukuran Pakaian pada Aplikasi Ruang Ganti Virtual," J. Teknol. Inf. dan Ilmu Komput., vol. 5, no. 2, p. 129, 2018.

[9] A. D. Savitri, F. A. Bachtiar, and N. Y. Setiawan, "Segmentasi Pelanggan Menggunakan Metode K-Means Clustering Berdasarkan Model RFM Pada Klinik Kecantikan (Studi Kasus : Belle Crown Malang)," J. Pengemb. Teknol. Inf. dan Ilmu Komput. Univ. Brawijaya, vol. 2, no. 9, pp. 2957-2966, 2018.

[10] A. F. Khairati, A. A. Adlina, G. F. Hertono, and B. D. Handari, "Kajian Indeks Validitas pada Algoritma K-Means Enhanced dan K-Means MMCA," Pros. Semin. Nas. Mat., vol. 2, pp. 161-170, 2019.

[11] B. N. Sari and A. Primajaya, "Penerapan Clustering Dbscan untuk Pertanian Padi di Kabupaten Karawang," JIKO (Jurnal Inform. dan Komputer) STMIK AKAKOM, vol. 4, no. 1, pp. 28-34, 2019.

[12] S. M. Kim, M. I. Peña, M. Moll, G. Giannakopoulos, G. N. Bennett, and L. E. Kavraki, "An evaluation of different clustering methods and distance measures used for grouping metabolic pathways," Proc. 8th Int. Conf. Bioinforma. Comput. Biol. BICOB 2016, no. BICoB, pp. 115-122, 2016.

[13] “Laporan Hasil Ujian Nasional,” 2018. [Online]. Available: https://hasilun.puspendik.kemdikbud.go.id/.

[14] A. E. Wicaksono, "Implementasi Data Mining Dalam Pengelompokan Peserta Didik di Sekolah untuk Memprediksi Calon Penerima Beasiswa Dengan Menggunakan Algoritma K-Means (Studi Kasus SMA N 6 Bekasi), Jur. Tek. Inform. Univ. Gunadarma, vol. 21, no. 3, pp. 206-216, 2016.

[15] N. Puspitasari, U. Mulawarman, H. Haviluddin, and U. Mulawarman, "PENERAPAN METODE K-MEANS DALAM PENGELOMPOKKAN CURAH HUJAN," Proc. Semin. Nas. Ris. Ilmu Komput. (SNRIK 2016), vol. I, no. December, 2016.

[16] S. F. Putra, R. Pradina, and I. Hafidz, "Feature Selection pada Dataset Faktor Kesiapan Bencana pada Provinsi di Indonesia Menggunakan Metode PCA (Principal Component Analysis),” J. Tek. ITS, vol. 5, no. 2, pp. 5-9, 2016. 